\title{
Arqueología de la Mixteca
}

\author{
Michael Lind
}

Hace cincuenta años, el doctor Ignacio Bernal (1958) escribió un breve resumen de la arqueología de la Mixteca. Bernal observó que los arqueólogos sabían muy poco sobre la Mixteca Alta y casi nada de la Mixteca Baja, no mencionó la Mixteca de la Costa. El propósito de este breve resumen de la arqueología de la Mixteca es señalar los avances que se han logrado desde entonces.

PALABRAS ClAVE: Mixteca Alta, Mixteca Baja, Mixteca de la Costa, yuhuitayu, aniñe

\section{Archeology of the Mixteca}

50 years ago, Ignacio Bernal wrote a brief summary of the archeology of the Mixteca. Bernal pointed out that the archeologists knew very little about the Mixteca Alta and close to nothing about the Mixteca Baja, he never mentioned the Mixteca de la Costa.The purpose of this essay is to show the advances made since 1958.

KeY WORDS: Mixteca Alta, Mixteca Baja, Mixteca de la Costa, yuhuitayu, aniñe

MICHAEL LIND: Santa Ana Unified School District, Estados Unidos. mikemyrn@sbcglobal.net 
MIXTECA ALTA, MIXTECA BAJA, MIXTECA DE LA COSTA,YUHUITAYU, ANIÑE

$\mathrm{L}$ a Mixteca está geográficamente dividida en tres partes: 1) la Mixteca Baja, una región cálida y seca que ocupa la parte norte de Oaxaca y el sur de Puebla, con elevaciones de alrededor de 1200 m; 2) la Mixteca Alta, una región templada y montañosa en el oeste de Oaxaca con elevaciones de más de 2000 m; y 3) la Mixteca de la Costa, una región tropical que se extiende a lo largo de la costa del Pacífico de Oaxaca (mapa 1). Las tres regiones fueron ocupadas por mixtecos antes de la llegada de los españoles, pero también habitaron en ella popolocas, chochos, ixcatecos, triquis y amuzgos. En el siglo XX los hablantes de mixteco constituyeron $90 \%$ de la población de la Mixteca, mientras que los hablantes de los otros idiomas representaron solamente $10 \%$ de la población, según un censo hecho por la Universidad Nacional Autónoma de México (UNAM) entre 1939 y 1949 (Rojas, Barragán y De la Cerda, 1957). Todos estos grupos lingüísticos pertenecen a la misma familia de idiomas y probablemente hablaron la misma lengua, el proto-otomangue, alrededor de 4400 a.C. (Hopkins, 1984: 43, fig. 1, p. 17).

\section{CRONOLOGÍA DE LA MIXTECA}

En los últimos cincuenta años los arqueólogos han establecido una cronología para las tres regiones de la Mixteca (tabla 1, p. XX). La ocupación más antigua de la Mixteca conocida hasta la fecha es del periodo Arcaico. Unas puntas de proyectil, fechadas estilísticamente entre 5000 a.C. y 3000 a.C. (Plunket, 1990: 357-358), así como un horno para cocinar pencas de maguey de Yuzanuu, fechado por radiocarbono entre 2100 a.C. y 2000 a.C. (Lorenzo, 1958), indican la presencia de grupos de cazadores-recolectores en el Valle de Nochixtlán de la Mixteca Alta.

Durante la fase Cruz Temprano hay mucha evidencia arqueológica del establecimiento de aldeas agrícolas en los Valles de Nochixtlán (Spores, 1972) y Tamazulapan (Byland, 1980) en la Mixteca Alta. La cerámica más antigua en la Mixteca, fechada por asociaciones de radiocarbono en 1300 a.C., es de la fase Cruz Temprano, descubierta por Spores (1972: 172) en Yucuita, en el Valle de Nochixtlán. Según Plunket (1990: 358-359), Yucuita cubría 65 hectáreas con una población estimada de 600 personas; posiblemente fue la comunidad más grande del estado de Oaxaca durante la fase Cruz Temprano. No se ha encontrado evidencia arqueológica de ocupación de la Mixteca Baja o la Mixteca de la Costa durante esta fase.

En la fase Cruz Medio sigue el desarrollo cultural en la Mixteca Alta en los valles de Nochixtlán y Tamazulapan. Según Plunket (1990: 359), Yucuita pierde mucha población y Etlatongo llega a ser el centro más importante del Valle de Nochixtlán. Blomster (2002) ha encontrado grandes figurillas huecas de cerámica llamadas "bebés huecos" en Etlatongo que sugieren la interacción entre la Mixteca Alta y la región de la costa del Golfo durante la fase Cruz Medio. También durante este periodo (fase Yutañusavi en la Mixteca Baja) existe evidencia arqueológica para la más antigua ocupación de la Mixteca Baja en el sitio de Santa Teresa, cerca de Huajuapan (Arriola y Palomares, 2000). El sitio de Santa Teresa se ha fechado en 1150 a.C. (Winter, 2007: 25). No se ha encontrado evidencia arqueológica para la ocupación de la Mixteca de la Costa durante esta fase.

En la fase Cruz Tardío, Yucuita llegó a cubrir 500 hectáreas y volvió a ser el centro más importante del Valle de Nochixtlán en la Mixteca Alta, donde existe por primera vez una jerarquía de tres niveles de comunidades y los primeros recintos ceremoniales encima de lomas (Plunket, 1990: 360-361). Durante esta fase, llamada Yododea en la Mixteca Baja, Rivera (2000) ha localizado y excavado sitios en la región de Tequixtepec y Chazumba.

También durante esta fase, llamada Charco en la Mixteca de la Costa, tuvo lugar la primera ocupación de aldeas agrícolas en la región del Río Verde. Joyce y sus colegas (1998) sugieren que la erosión causada por la agricultura en la Mixteca Alta durante las fases Cruz Temprano y Medio resultó en la formación de suelos aluviales que formaron valles fértiles a lo largo de los ríos de la costa y que permitieron, por primera vez, la agricultura en esta región. Es probable que los ancestros de los chatinos, y no los mixtecos, fueran los que ocuparon la Mixteca de la Costa durante esta fase. 
Mexico

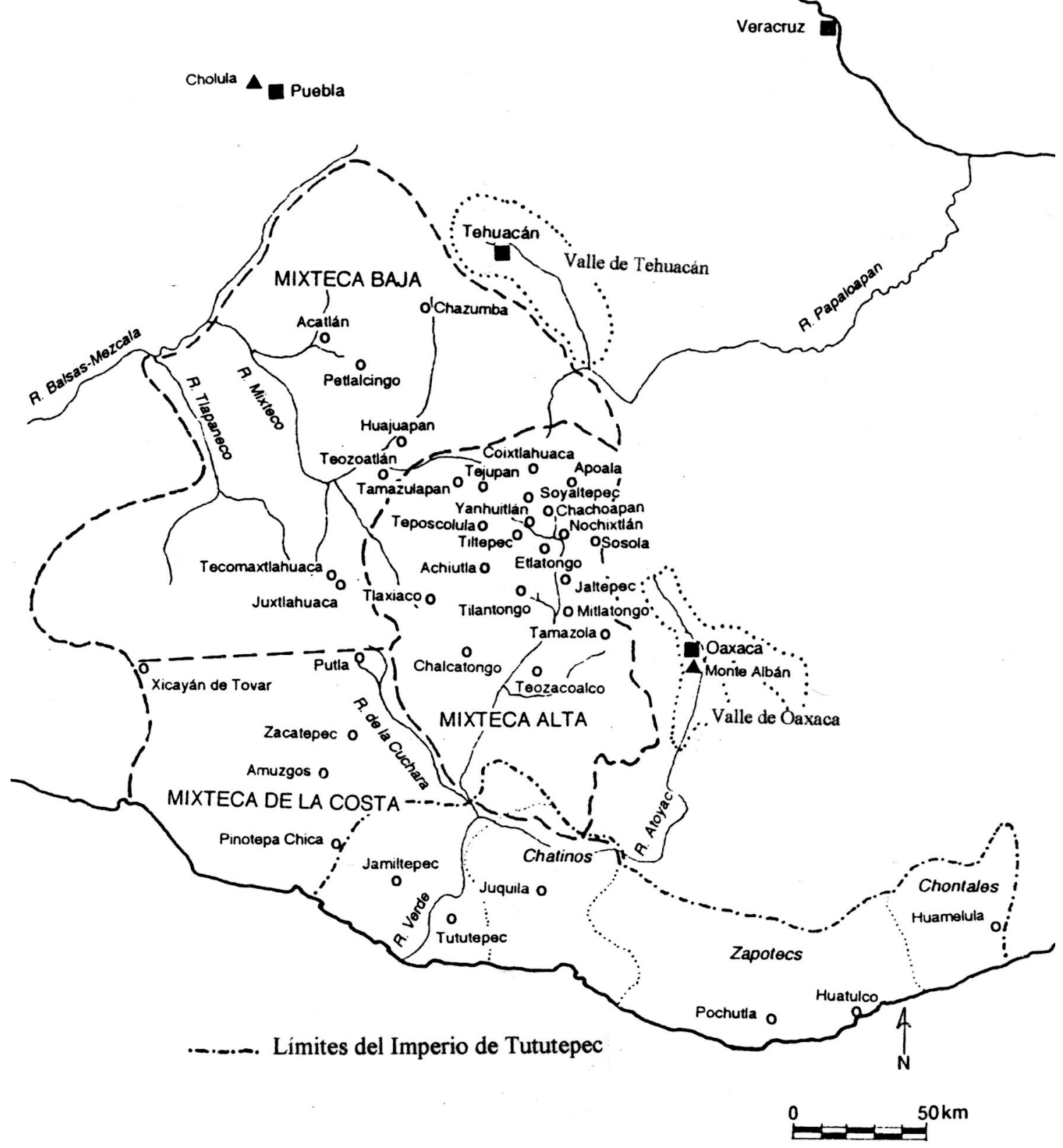


Tabla 1. Cronología de la Mixteca

(Fases para la Mixteca Alta y Mixteca Baja tomadas de Winter, 2007; Fases para la Mixteca de la Costa de Joyce et. al., 1998)

\begin{tabular}{|c|c|c|c|c|}
\hline & Mixteca Alta & Mixteca Baja & Mixteca de la Costa & \\
\hline 1200 & NATIVIDAD & NUYOO & & \\
\hline \multicolumn{5}{|l|}{1100} \\
\hline 1000 & Temprano & Temprano & YUGÜE & \multirow{2}{*}{$\begin{array}{l}\text { Fecha más antigua en } \\
\text { los códices } \mathrm{f}-942 \mathrm{~d} . \mathrm{C} \text {. }\end{array}$} \\
\hline 900 & & & & \\
\hline \multicolumn{5}{|l|}{800} \\
\hline 700 & Tardío & & YUTA TIYOO & \\
\hline \multicolumn{4}{|l|}{600} & \multirow{2}{*}{$\begin{array}{l}\text { Sistema de escritura } \\
\text { ñuiñe }\end{array}$} \\
\hline 500 & LAS FLORES & NUUIÑE & & \\
\hline 400 & & & COYUCHE & \\
\hline 300 & Temprano & & & \\
\hline 200 & & & CHACAHUA & \multirow{2}{*}{$\begin{array}{l}\text { Escritura más antigua } \\
\text { en Huamelulpan }\end{array}$} \\
\hline 100 & & & & \\
\hline a.C. 0 d.C. & RAMOS & NUDEE & MINIYUA & \\
\hline \multicolumn{5}{|l|}{-100} \\
\hline-200 & & & MINIZUNDO & \\
\hline-300 & YUCUITA & YODODEA & & \\
\hline-400 & CRUZ Tardío & & & \\
\hline-500 & Cruz D & & CHARCO & \multirow{2}{*}{$\begin{array}{l}\text { Ocupación conocida más } \\
\text { antigua en la Costa }\end{array}$} \\
\hline-600 & & YUTAÑUUSAVI & & \\
\hline-700 & Cruz C & & & \\
\hline-800 & & & & \multirow{2}{*}{$\begin{array}{l}\text { Figurillas huecas estilo } \\
\text { Olmeca en Etlatongo }\end{array}$} \\
\hline-900 & CRUZ Medio & & & \\
\hline \multicolumn{5}{|l|}{-1000} \\
\hline-1100 & Cruz B & Santa Teresa & & \multirow{2}{*}{$\begin{array}{l}\text { Ocupación conocida más } \\
\text { antigua en la Mixteca } \\
\text { Baja }\end{array}$} \\
\hline-1200 & & & & \\
\hline-1300 & CRUZ Temprano & & & \multirow{2}{*}{$\begin{array}{l}\text { Cerámica más antigua } \\
\text { en la Mixteca-Yucuita }\end{array}$} \\
\hline-1400 & Cruz A & & & \\
\hline \multicolumn{5}{|l|}{-1500} \\
\hline \multicolumn{5}{|l|}{-1600} \\
\hline \multicolumn{5}{|l|}{-1700} \\
\hline \multicolumn{5}{|l|}{-1800} \\
\hline \multicolumn{5}{|l|}{-1900} \\
\hline \multicolumn{5}{|l|}{-2000} \\
\hline-2100 & YUZANUU & & & \multirow{2}{*}{$\begin{array}{l}\text { Ocupación más antigua } \\
\text { fechada en la Mixteca }\end{array}$} \\
\hline a.C -2200 & & & & \\
\hline
\end{tabular}




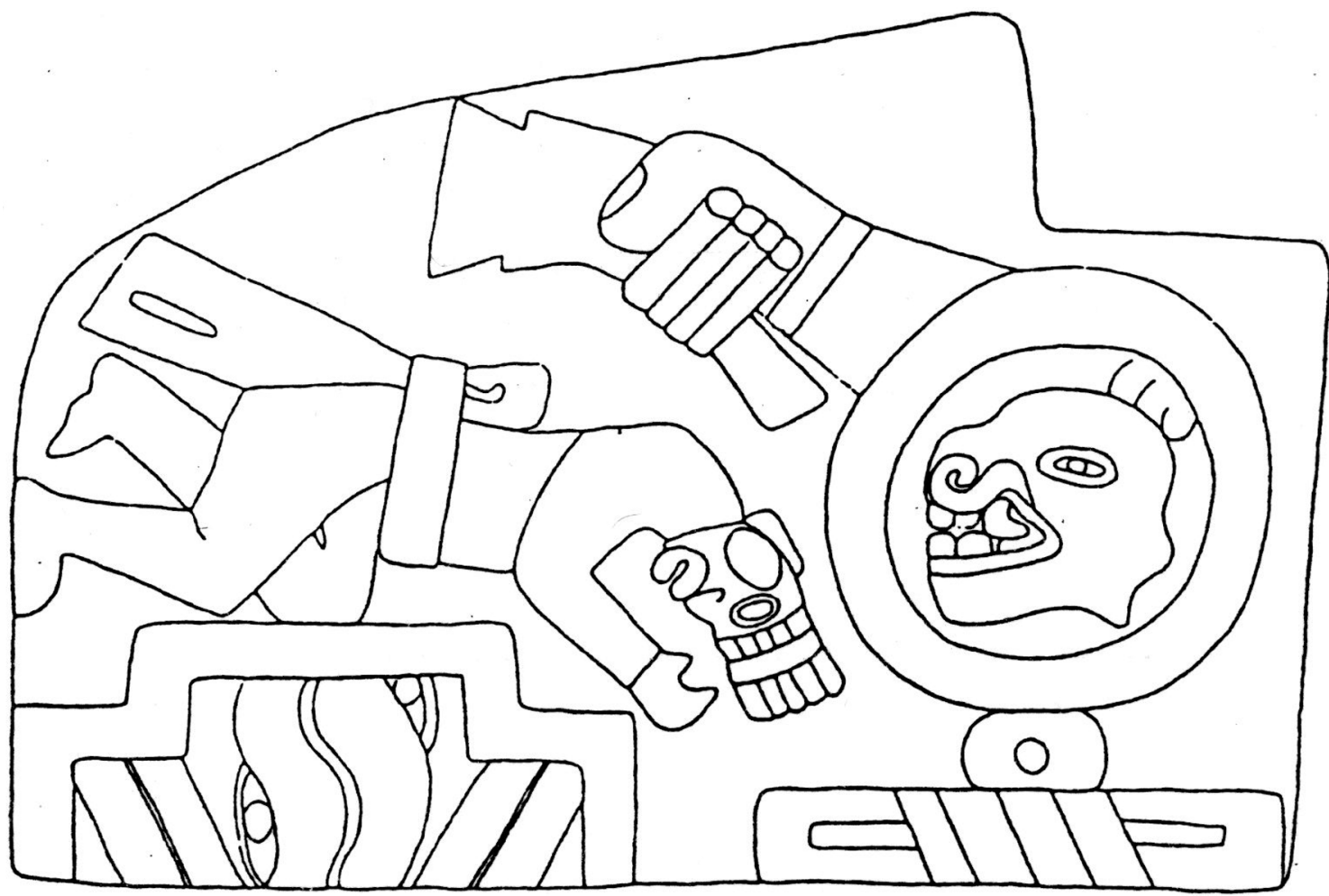

Figura 1. Piedra grabada con escritura ñuiñe de Cerro de la Caja, fase Ñuiñe (Rivera, 2000: 10, fig. 3).

Durante las fases Ramos y Ñudee se desarrollaron numerosos centros urbanos con arquitectura ceremonial y evidencia de diferencias en rangos sociales en los sitios de Monte Negro (Caso, 1938), Yucuita (Winter, 1997), Huamelulpan (Gaxiola, 1984), Cerro de las Minas (Winter, 2007) y otros sitios en la Mixteca Alta y Baja. Estos sitios fueron probablemente los centros de jefaturas que batallaban entre sí y cuyos guerreros solían cortarles la cabeza a los enemigos como trofeos de guerra, lo cual ocurría también en Monte Negro, Yucuita y Huamelulpan (Winter, 1990: 77). Evidencia de la escritura más antigua en la Mixteca existe en Huamelulpan y es escritura de estilo zapoteco (Gaxiola, 1984: 77).

En las fases Las Flores y Nuiñe, grandes centros urbanos localizados sobre los cerros se establecen en Yucuñudahui (Caso, 1938), en la Mixteca Alta; en Cerro de las Minas (Winter, 2007) y Cerro de la Caja (Rivera y Piña Chán, 2005) en la Mixteca Baja, y en otros sitios de la Mix- teca Alta y Baja. Un estilo de escritura, llamado ñuiñe (Paddock, 1966; Moser, 1977; Rodríguez, Rivera y Martínez, 1996; Urcid, 1996), existió en la Mixteca Baja, especialmente en el área de Tequixtepec y Chazumba, pero también se encuentra en partes de la Mixteca Alta (Rivera, 2004). Rivera (2000) dice que las piedras grabadas en estilo ñuiñe muestran a los gobernantes —identificados por glifos que dan sus nombres calendáricos- y los lugares que conquistaron, identificados por glifos toponímicos (fig. 1). El sistema de escritura zapoteca, probablemente asociado con los chatinos y zapotecos, existió en la Mixteca de la Costa (Urcid, 1993). Los centros urbanos de la fase Las Flores probablemente encabezaron pequeños estados competitivos que fueron los antecesores de los reinos mixtecos del Posclásico. 

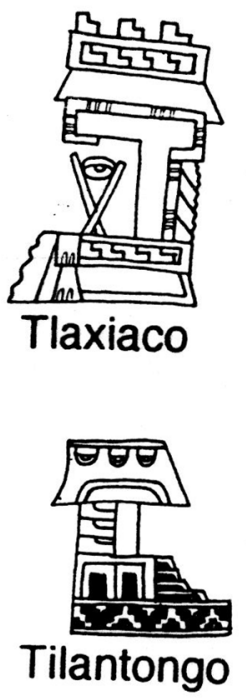

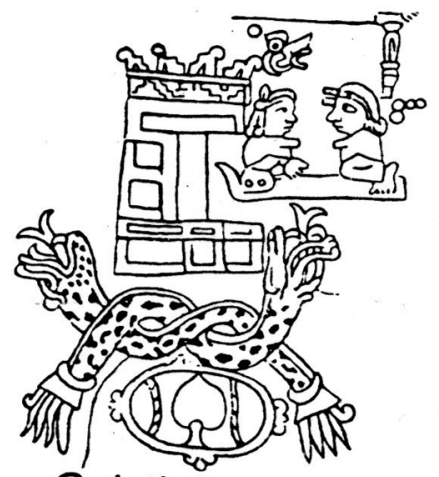

Coixtlahuaca

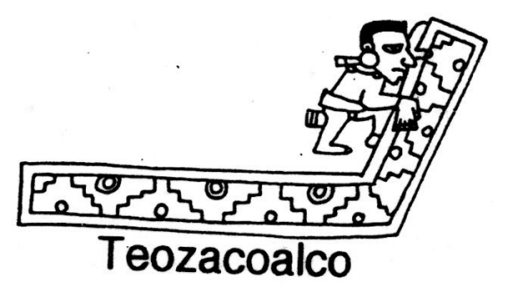

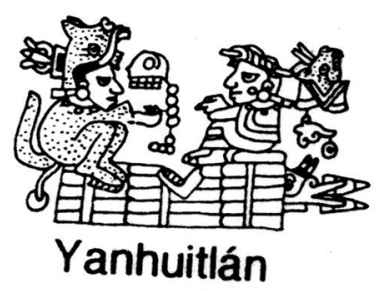

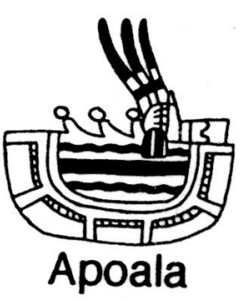

MIXTECA ALTA

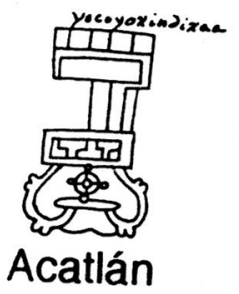

MIXTECA BAJA

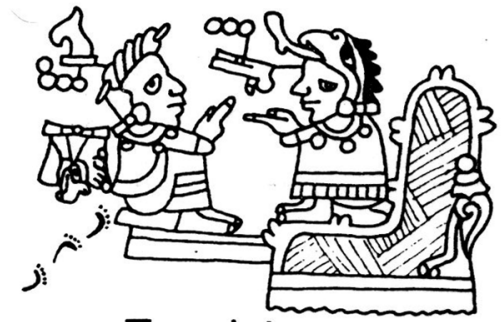

Tequixtepec

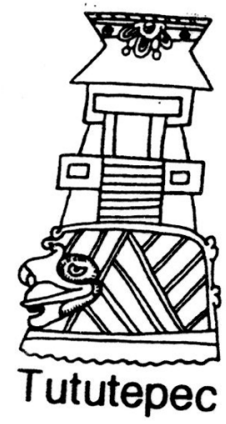

MIXTECA DE LA COSTA

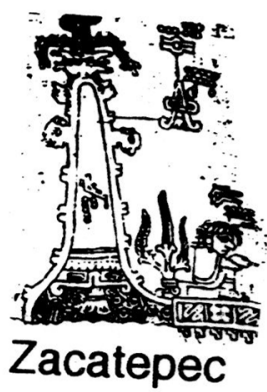

Figura 2. Glifos toponímicos de algunos pueblos mixtecos (Smith, 1973). 


\section{EL POSCLÁSICO}

En el Posclásico Temprano se desarrollaron los reinos mixtecos junto con los códices que relatan acontecimientos históricos que comienzan en 942 d.C. (Rabin, 2002). En la Mixteca Alta, el famoso héroe mixteco, Señor 8 Venado de Tilantongo, estableció el reino de Tututepec en la región del Río Verde en la Mixteca de la Costa. El reino de Tututepec conquistó a los chatinos, zapotecos y chontales que vivían en la costa para establecer el imperio de Tututepec (Spores, 1993).

La mayoría de los sitios arqueológicos del Posclásico se encuentra cerca de los pueblos actuales localizados en el mapa 1 (p. 15). Los nombres de los pueblos mixtecos fueron escritos con glifos topónimos en los códices mixtecos (M. E. Smith, 1973). Se han descifrado algunos de estos glifos topónimos, pero la mayoría de ellos queda aún sin identificar (fig. 2, p. 18).

\section{REINOS MIXTECOS}

Cada reino mixteco consistía en un solo pueblo o, de manera más frecuente, de varios pueblos entre los cuales uno era la capital del reino y los otros eran sus sujetos (Spores, 1967: 100-101). Terraciano (2001: 103-104) ha señalado que "reino" en mixteco es yuhuitayu y que es un juego de palabras de esta lengua, ya que tiene dos sentidos. Yuhui significa 'petate', en el sentido de 'lugar del gobernante', y tayu, 'asiento' o 'pareja'. Yuhuitayu, entonces, significa lugar del asiento del gobernante' y 'lugar de la pareja real'. En los códices se ve la pareja real (tayu) sentada en un petate (yuhui) como gobernantes del reino o yuhuitayu (Terraciano, 2001: 158).

Spores (1983a, 1983b, 1983c) ha identificado unos cuarenta yuhuitayu o reinos mixtecos en la Mixteca Alta, Baja y de la Costa. Autry (1997) ha hecho un estudio detallado de la Suma de Visitas, un censo español hecho entre 1547 y 1550, que da la población de treinta de los yuhuitayu mixtecos identificados por Spores y el número de sus barrios (siqui) y sujetos ( $\tilde{n} u u)$. El censo indica que los yuhuitayu mixtecos tenían poblaciones de 400 a 18000 habitantes, pero que la mayoría eran de 1000 a 3000 personas (tabla 2, p. 20).
La capital era la comunidad más grande del yuhuitayu. Por ejemplo, Jaltepec, con una población de 4819 personas, era la capital de un yuhuitayu con seis sujetos o ñuu. Los seis ñuu tenían poblaciones de 475 a 741 personas. La población total del yuhuitayu de Jaltepec era de 8308 personas. Mitlatongo, con una población de 1406 personas, era la capital de un yuhuitayu con cinco estancias o $\tilde{n} u u$ con poblaciones de 59 a 242 personas. La población total del yuhuitayu de Mitlatongo era de 2083 personas. La capital era la comunidad más grande del yuhuitayu y también el centro político, económico y religioso del reino.

Autry (1997), con base en la Suma de Visitas, que proporciona algunos datos sobre los tamaños de los yuhuitayu, cita un promedio de $310 \mathrm{~km}^{2}$ para los yuhuitayu de la más densamente poblada Mixteca Alta, y 800 km² para la Mixteca Baja y de la Costa, con menor densidad de población. También Autry calculó la densidad de población para estas regiones y estimó que los yuhuitayu de la Mixteca Alta tenían un promedio de 24 personas por $\mathrm{km}^{2}$, los de la Mixteca Baja de 4.5 personas por $\mathrm{km}^{2}$ y los de la Mixteca de la Costa de 1.5 personas por $\mathrm{km}^{2}$.

M. E. Smith (1973: cap. VII) hizo un excelente estudio del yuhuitayu de Zacatepec en la Mixteca de la Costa. Zacatepec era la capital de un reino con 12 estancias o ñuu y una población de 2178 habitantes. El Lienzo de Zacatepec (c. 1540-1560 d.C.) registra los linderos del yuhuita$y u$, localiza sus estancias $(\tilde{n} u u)$ con sus glifos topónimos e identifica los nombres calendáricos de los nobles que gobernaron las estancias. El yuhuitayu de Zacatepec cubrió 1740 km², el doble del promedio citado por Autry para la Mixteca de la Costa. Sin embargo, la densidad de población del yuhuitayu de Zacatepec era de 1.25 personas por $\mathrm{km}^{2}$, porcentaje muy cercano al de 1.5 personas por $\mathrm{km}^{2}$ citado por Autry para la Mixteca de la Costa.

Spores (1983c: 255) ha caracterizado los yuhuitayu como pequeños estados socialmente estratificados y gobernados por una aristocracia privilegiada. Comprendían un territorio que generalmente podía ser atravesado a pie en un día, y una o más comunidades con terrenos de cultivo y áreas de recursos adyacentes. La sociedad del yuhuitayu estaba organizada en tres estratos sociales: la realeza, la nobleza y los comuneros. En algunos casos, la realeza tenía directamente bajo su control a un grupo de siervos. 
Tabla 2. Poblaciones de unos yuhuitayu mixtecos

(Yuhuitayu identificados por Spores, 1983abc; Poblaciones, barrios, y sujetos según Autry, 1997)

\begin{tabular}{|c|c|c|c|c|}
\hline Capital (Población) & Localización & Barrios & Sujetos* & Población total \\
\hline Tlaxiaco (5 353) & Alta & - & $8 / 31^{*}$ & 17892 \\
\hline Yanhuitlán & Alta & 14 & 16 & 16260 \\
\hline Teposcolula (12 503) & Alta & 6 & - & 12503 \\
\hline Coixtlahuaca & Alta & - & - & $12000^{\star *}$ \\
\hline Jaltepec (4 819) & Alta & 6 & 6 & 8308 \\
\hline Teozacoalco (2 408) & Alta & 7 & $23^{*}$ & 7093 \\
\hline Tamazulapan & Alta & - & 6 & 4442 \\
\hline Tututepec (3 564) & Costa & - & - & 3564 \\
\hline Acatlán & Baja & - & $1^{*}$ & 3233 \\
\hline Achiutla (32 05) & Alta & 4 & - & 3205 \\
\hline Tilantongo & Alta & - & 5 & 3152 \\
\hline Apoala & Alta & - & 10 & 3023 \\
\hline Tamazola & Alta & - & $14^{*}$ & 2396 \\
\hline Putla & Costa & - & $3^{*}$ & 2376 \\
\hline Zacatepec & Costa & - & $12^{*}$ & 2178 \\
\hline Sosola (1 592) & Alta & - & $1^{*}$ & 2150 \\
\hline Mitlatongo (1 406) & Alta & 5 & $5^{*}$ & 2083 \\
\hline Huajuapan & Baja & - & - & $2000^{* *}$ \\
\hline Teozoatlán & Baja & - & 8 & 1638 \\
\hline Xicayán de Tovar & Costa & - & $10^{*}$ & 1584 \\
\hline Pinotepa Chica & Costa & - & $7^{\star}$ & 1584 \\
\hline Juxtlahuaca (1 415) & Baja & - & - & 1415 \\
\hline Nochixtlán & Alta & - & 4 & 1372 \\
\hline Soyaltepec (1 361) & Alta & 6 & - & 1361 \\
\hline Tejupan (1 355) & Alta & 6 & - & 1355 \\
\hline Amuzgos & Costa & - & $4^{*}$ & 950 \\
\hline Etlatongo & Alta & - & 8 & 855 \\
\hline Jamiltepec & Costa & - & $3^{*}$ & 792 \\
\hline Chachoapan (719) & Alta & - & - & 719 \\
\hline Chazumba (594) & Baja & - & - & 594 \\
\hline Tiltepec (486) & Alta & - & - & 486 \\
\hline Petlalcingo (412) & Baja & - & - & 412 \\
\hline
\end{tabular}

${ }^{*}$ Las dependencias están enlistadas en la Suma de Visitas como sujetos y/o estancias. Las estancias están marcadas por un asterisco $\left({ }^{*}\right)$.

** Estos pueblos no están en la Suma de Visitas; sus poblaciones vienen de un censo de 1570 d.C. (Dahlgren, 1954: 36-37). La primera línea en esta página debe colocarse debajo de la tabla 


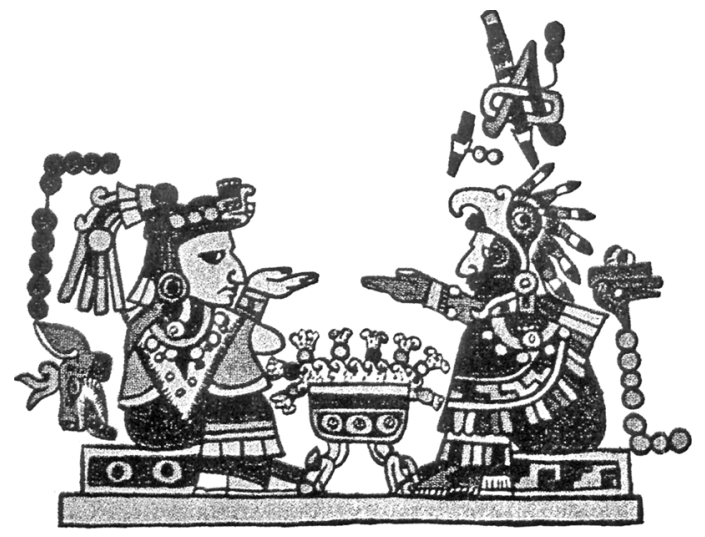

Figura 3. Casamiento real mixteco en la p. 5 del Códice Nutall. La novia le da al novio un cajete trípode de chocolate (Nutall, 1975: 5).

\section{LA REALEZA MIXTECA}

Cada yuhitayu era gobernado por una pareja real o tayu, el rey o iya, y la reina o iya dzehe (Terraciano, 2001: 158). Los herederos de los yuhuitayu solamente podían casarse con parejas reales. Por eso, un heredero al trono de un yuhuitayu tenía que casarse con una princesa, la hija de un rey y una reina; y una heredera al trono de un yuhuitayu tenía que casarse con un príncipe, el hijo de un rey y una reina. Por supuesto, el mejor arreglo era el casamiento entre un príncipe y una princesa que eran herederos de dos o más yuhuitayu (Spores, 1974).

Antes de casarse se decidía cuál de los hijos o hijas de la pareja heredaría el yuhuitayu; o si los dos llegaban a ser gobernantes de diferentes yuhuitayu, se elegía quién heredaría el yuhuitayu del padre y quién el de la madre. A su vez, fue posible combinar la herencia de los yuhuitayu con la alianza de hijos e hijas herederos. En la Mixteca Alta los novios herederos, junto con sus padres reales, consultaban a los nobles de sus yuhuitayu y también iban al centro religioso de Achiutla para consultar al oráculo del dios solar la forma de establecer la herencia (Spores, 1967: 146).

Al casarse la novia le ofrecía al novio una vasija de chocolate (M. E. Smith, 1973: 31). Estas vasijas, que se ven representadas en los códices, eran ollas o cajetes trípodes de cerámica polícroma mixteca del tipo Pilitas (figs. 3-4). Se han encontrado muchas de estas vasijas polícromas

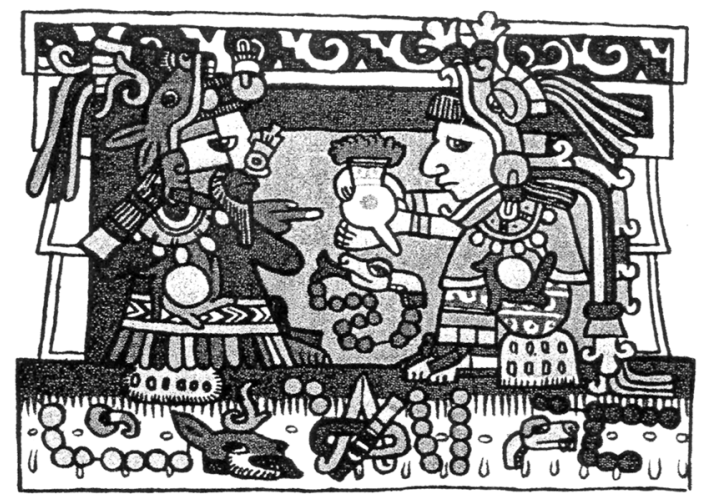

Figura 4. Casamiento real mixteco en la p. 26 del Códice Nutall. La novia le da al novio una olla trípode de chocolate (Nutall, 1975: 26).

(figs. 5-6, pp. 22-23) en excavaciones asociadas con casas de nobles y reyes en la Mixteca Alta (Lind, 1987). Un fechamiento en radiocarbono de 1340 d.C. de Yucuita es el año más antiguo que tenemos hasta ahora para la cerámica polícroma Pilitas en la Mixteca (Lind, 1994).

Cuando los reyes morían eran enterrados por sacerdotes a medianoche en cuevas o "sótanos" excavados en los campos o en los montes fuera del pueblo (Dahlgren, 1954: 336). Los "sótanos" eran pozos excavados en la tierra que después se sellaban con una gran piedra, como los reportados por Bernal (1949) en Coixtlahuaca (fig. 7, p. 23). El muerto quedaba envuelto en un petate atado con mecates y su cara se cubría con una máscara de madera adornada con mosaicos de turquesa y concha. El cadáver se enterraba en posición sedente (fig. 8 , p. 24).

El aniversario de la muerte del gobernante del yuhuitayu se celebraba en todo el reino en el día de su nacimiento (Dahlgren, 1954: 349). De las pocas figurillas de cerámica encontradas en las excavaciones de casas posclásicas, la mayoría parecen representar a gobernantes muertos (Lind, 1987). Las figurillas tienen los labios estirados sobre los dientes, semejando una "sonrisa" de muertos, las mejillas hundidas y los ojos protuberantes como muertos (fig. 9, p. 24). Algunas figurillas con cuerpos tienen los brazos sobre el pecho y las piernas dobladas hacia el estómago en posición fetal, que es la manera en que se enterraban 


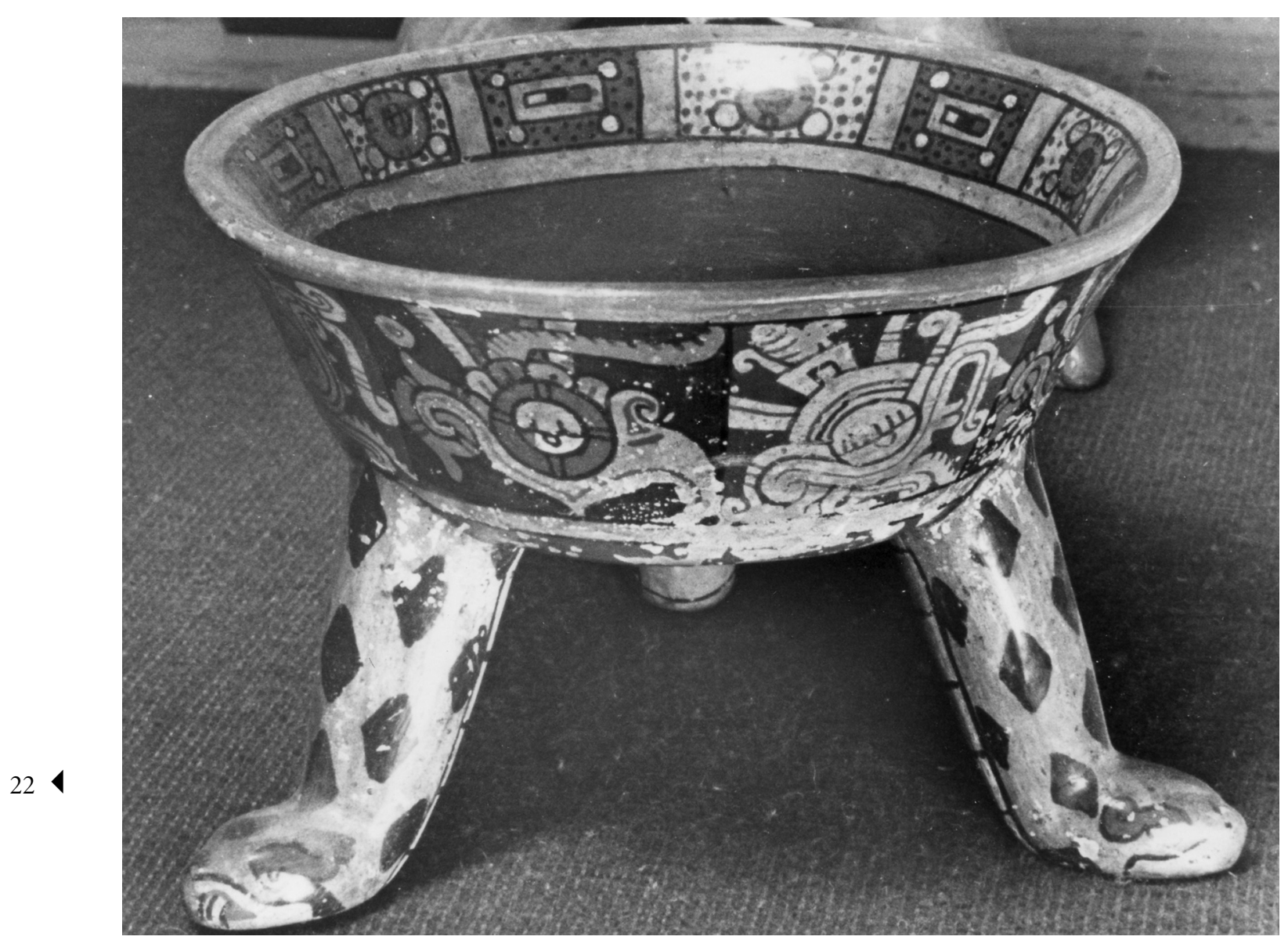

Figura 5. Vasija trípode de cerámica polícroma.

a los muertos (fig. 10, p. 25). Es posible que hayan usado las figurillas en ceremonias de celebración de los aniversarios de los gobernantes muertos.

\section{LOS CÓDICES}

Para registrar las genealogías de sus gobernantes, los herederos guardaban códices en la capital de cada yuhuita$y u$. En estos libros se registraban los nacimientos, los casamientos y las muertes de los gobernantes del yuhuitayu y su historia por un periodo de tiempo que alcanzó hasta medio milenio (Spores, 1967: 94-96). Más allá de la historia registrada, los códices proveen las fechas míticas o rituales en que los ancestros divinos fundaron el yuhuitayu. Rabin (2002) ha identificado once parejas divinas que constituyeron los ancestros divinos de las dinastías mixtecas históricas. También los códices incluían los nombres de sus pueblos sujetos o ñuu y los nobles que los gobernaban. Los escribanos que pintaban los códices eran hijos de nobles educados para ser los historiadores del yuhuitayu (Burgoa, 1989: I, 210).

\section{LOS PALACIOS REALES}

La pareja real del yuhuitayu vivía en un enorme palacio, llamado aniñe, en mixteco (Terraciano, 2001: 158). En 


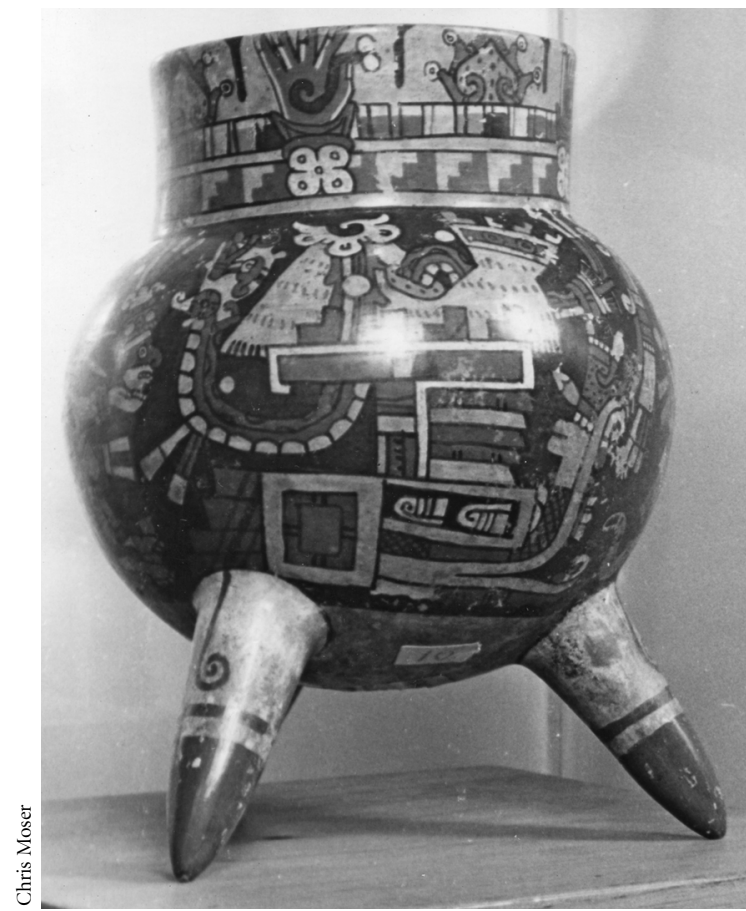

Figura 6. Olla trípode de cerámica polícroma. Pilitas de Nochixtlán, fase Natividad Tardío, Museo Nacional de Antropología.

su segunda Carta de Relación, escrita el 30 de octubre de 1520 d.C., Hernán Cortés (1963: 46) relata que sus soldados habían visto un palacio en Tamazulapan, en la Mixteca Alta, que era más grande y mejor edificado que el castillo de Burgos en España. Byland (1980) ha localizado las ruinas de este aniñe y ha determinado que cubría $5000 \mathrm{~m}^{2}$. Las ruinas del palacio colonial del rey de Yanhuitlán todavía están a la vista. El palacio consiste en cuartos dispuestos alrededor de nueve patios y cubre más de $6000 \mathrm{~m}^{2}$. Spores (1972) excavó en uno de estos patios y encontró restos de otro más antiguo, que posiblemente corresponde al aniñe prehispánico de Yanhuitlán.

Hasta hace poco no se había excavado ningún aniñe prehispánico en la Mixteca, pero recientemente Spores y sus colegas del Proyecto Arqueológico de Teposcolula comenzaron la excavación del enorme palacio posclásico (aniñe) del rey del Pueblo Viejo de Teposcolula, llamado Yucundaa en mixteco (Spores, 2005). El aniñe está localizado en la parte más alta de un cerro que alcanza una al-

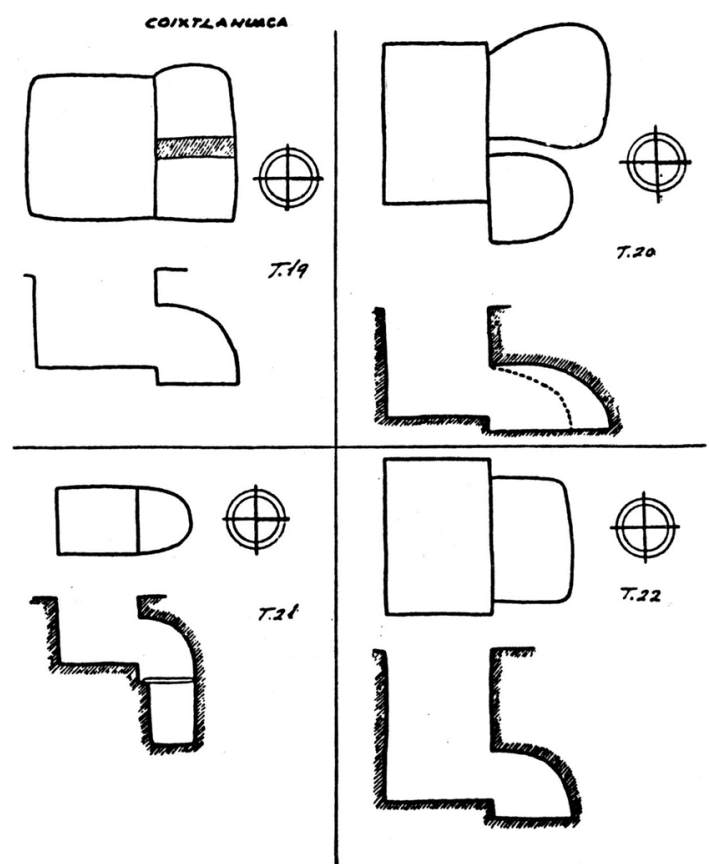

Figura 7. "Sótanos" en Coixtlahuaca, fase Natividad Tardío (Bernal, 1949: 21, plano 8).

tura de $220 \mathrm{~m}$ sobre el Valle de Teposcolula (Spores, 2005: 70). Comprende tres secciones: residencial, cívica-administrativa y ritual (Diego, 2007).

La sección residencial tiene numerosos patios con cuartos alrededor conectados por pasillos y escaleras. Algunos cuartos tienen sus fachadas adornadas con "endeques" grabados (piedras de color blanco y blandas como el gis) que muestran figuras humanas en el estilo de los códices mixtecos. La sección cívica-administrativa tiene cuatro grandes edificios con columnas colocadas alrededor de una plaza. Los muros de algunos de los edificios están decorados con diseños de petates y una serie de discos, símbolos de la realeza. La sección ritual tiene la plaza más grande del aniñe. En el lado este, la plaza tiene el montículo más grande de todo el sitio, probablemente un templo. Al norte de la plaza hay otro montículo, posiblemente otro templo. Parece que todo el aniñe tenía un muro alrededor con entradas restringidas (Diego, 2007).

Los aniñe eran las residencias de la familia real y sus 


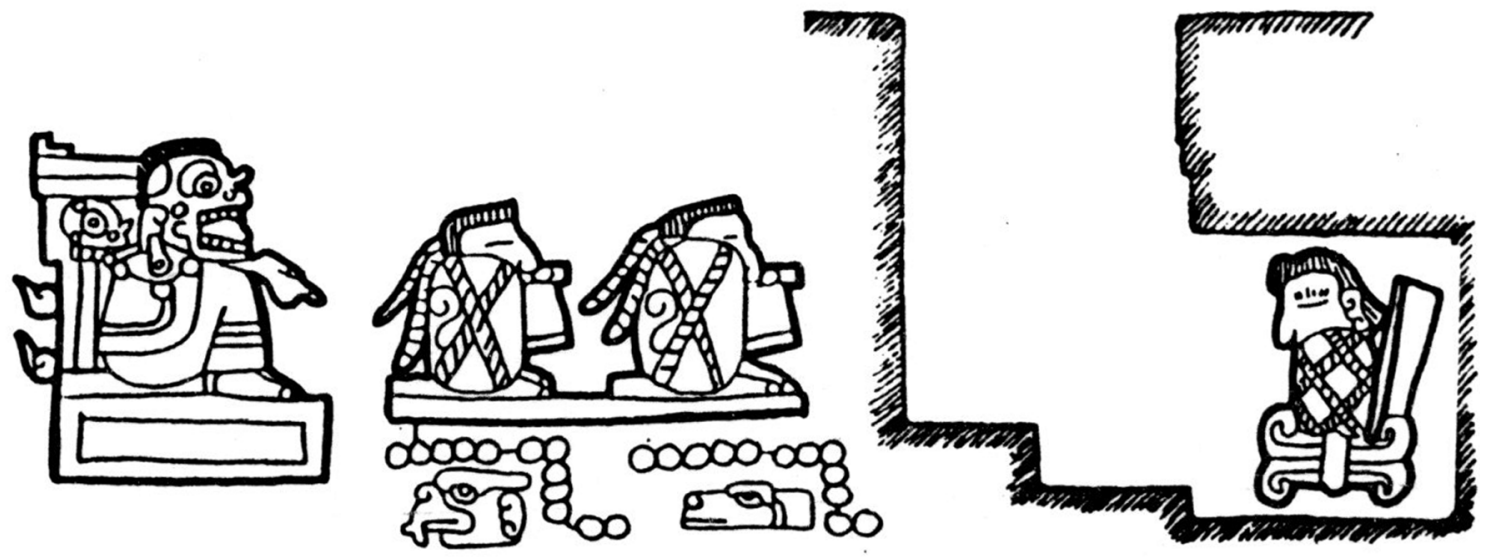

Figura 8. Entierros mixtecos en bultos mortuorios (modificado de Pohl, 1994b: 73).

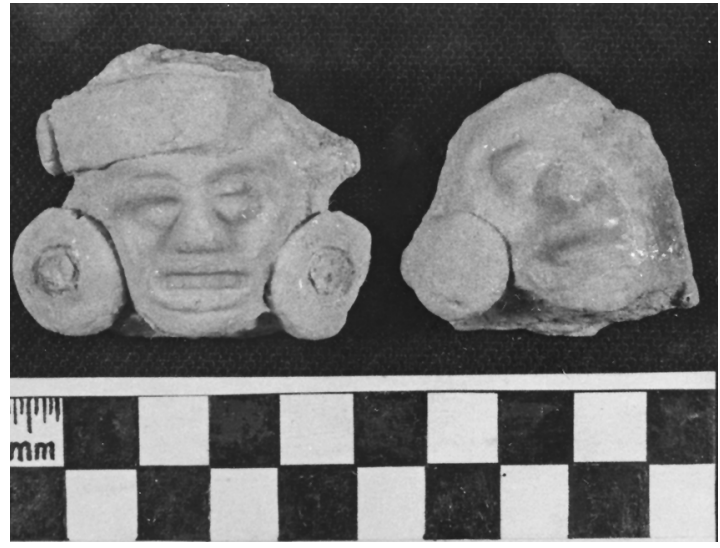

Figura 9.

parientes junto con sus sirvientes y, posiblemente, con las familias nobles de los consejeros y sacerdotes. Su sección cívico-administrativa era para conferencias y banquetes a los que asistían los nobles del yuhuitayu, como se puede ver en el Códice de Yanhuitlán (Sepúlveda y Herrera, 1994: 99). Pohl (1994a) comenta que había talleres de especialistas que hacían joyas, textiles finos y cerámica policroma en los aniñe pero, hasta la fecha, no se han encontrado estos talleres de especialización en el aniñe de Yucundaa (Diego, 2007). Por otra parte, es evidente que se llevaron a cabo actividades religiosas en la sección ritual del aniñe (Diego, 2007).

\section{LA NOBLEZA MIXTECA}

Cada rey mixteco escogía a cuatro nobles para servirle de consejeros, de los cuales uno era el consejero supremo (Spores, 1984: 77). Pohl (1994b: 36-38) ha notado que estos consejeros eran parientes cercanos de los reyes y que aparecen vestidos de sacerdotes en los códices (fig. 11). Tenían a cargo los bultos sagrados del yuhuitayu y el consejero supremo se encargaba de los asuntos militares del reino. Aparte del consejo, Pohl (1994b: cap. III) dice que un sacerdote yaha-yahui (águila-serpiente de fuego), representado en los códices, se encargaba de la tesorería real, encabezaba las ceremonias religiosas públicas y era sacrificador de humanos (fig. 12, p. 26).

Los reyes también nombraban a nobles para gobernar a los comuneros que ocupaban los barrios, siqui en mixteco (Terraciano, 2001: 105), y a los pueblos sujetos, ñuu en mixteco (Terraciano, 2001: 104). Estos nobles residían en el siqui o $\tilde{n} u u$ que gobernaban y eran parientes del rey (Dahlgren, 1954: 171). El Lienzo de Zacatepec muestra a los nobles, con sus nombres calendáricos, que gobernaron los ñuu identificados por los glifos topónimos (M. E. Smith, 1973: 112). También el Códice de Yanhuitlán muestra a un grupo de nobles en una conferencia con el rey de Yanhuitlán, Señor 9 Casa, en su aniñe en el año 1532. El gobernante 9 Casa está acompañado por su consejero supremo y tres individuos más que pueden ser los otros consejeros (Sepúlveda y Herrera, 1994: 99). Ade- 
más, el códice muestra a un noble, Señor 8 Venado, administrador de un ñuu sujeto a Yanhuitlán, mandando tributo del $\tilde{n} u u$ al aniñe de Yanuitlán (Sepúlveda y Herrera, 1994: 100).

Se han excavado casas de nobles en Coixtlahuaca (Bernal, 1949), Chachoapan y Yucuita (Lind, 1979). Son más pequeñas que las secciones residenciales de los palacios reales (aniñe), pero más grandes y mejor construidas que las casas de comuneros. Incluyen cuartos con pisos de estuco rojo arreglados alrededor de patios con pisos de estuco blanco.

Más impresionante, sin embargo, es la construcción de los muros exteriores de las casas. Consisten en grandes lozas de endeque que alternan con secciones más pequeñas rellenas de este mismo material (fig. 13, p. 27). Bernal (1949) identificó este sistema de construcción de muros en Coixtlahuaca y lo señaló por primera vez como distintivo de la Mixteca. También existe en las casas de nobles de Chachoapan y Yucuita (Lind, 1979) y en el aniñe de Yucundaa en Teposcolula (Diego, 2007). Winter (2007) relata que este sistema de construcción se remonta al periodo Clásico de la fase Nuiñe en el Cerro de las Minas en la Mixteca Baja, y también al periodo Clásico de la fase Las Flores en Yucuñudahui en la Mixteca Alta. Hay una larga tradición en la Mixteca de usar este sistema de construcción tan distintivo.

Unos artefactos curiosos que se encuentran asociados con las casas de nobles son los penates. Aunque 'penate' es la palabra latina para "dios de la casa", es evidente que estas pequeñas figuras grabadas en piedra (generalmente

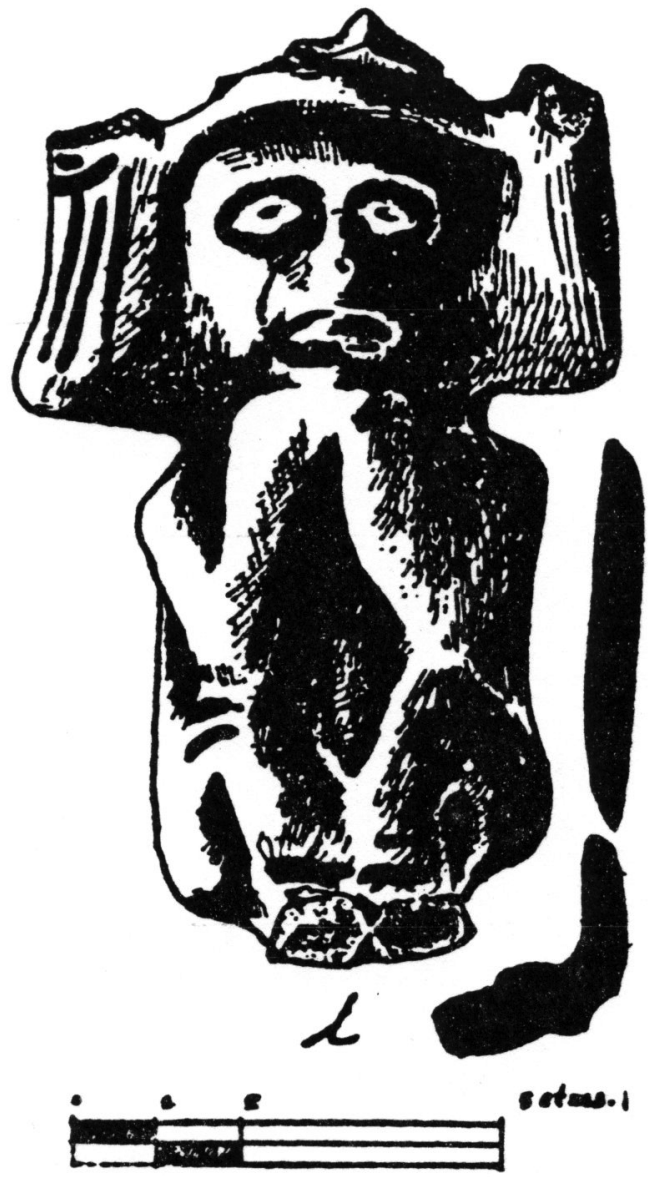

Figura 10.

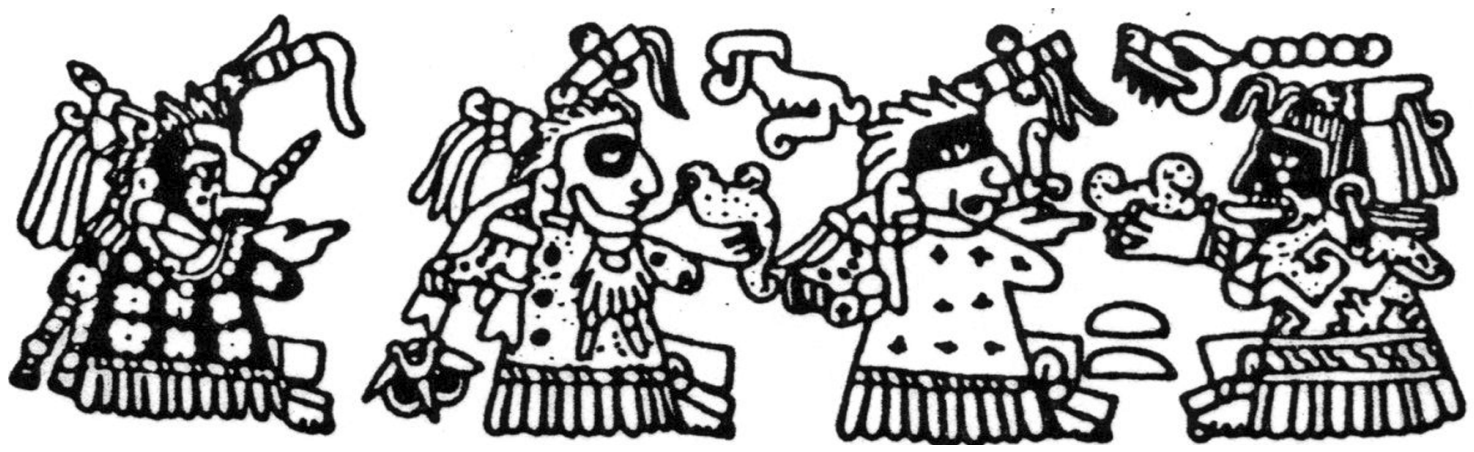

Figura 11. Los consejeros reales mixtecos (modificado de Pohl, 1994:b: 66, fig. 27. 

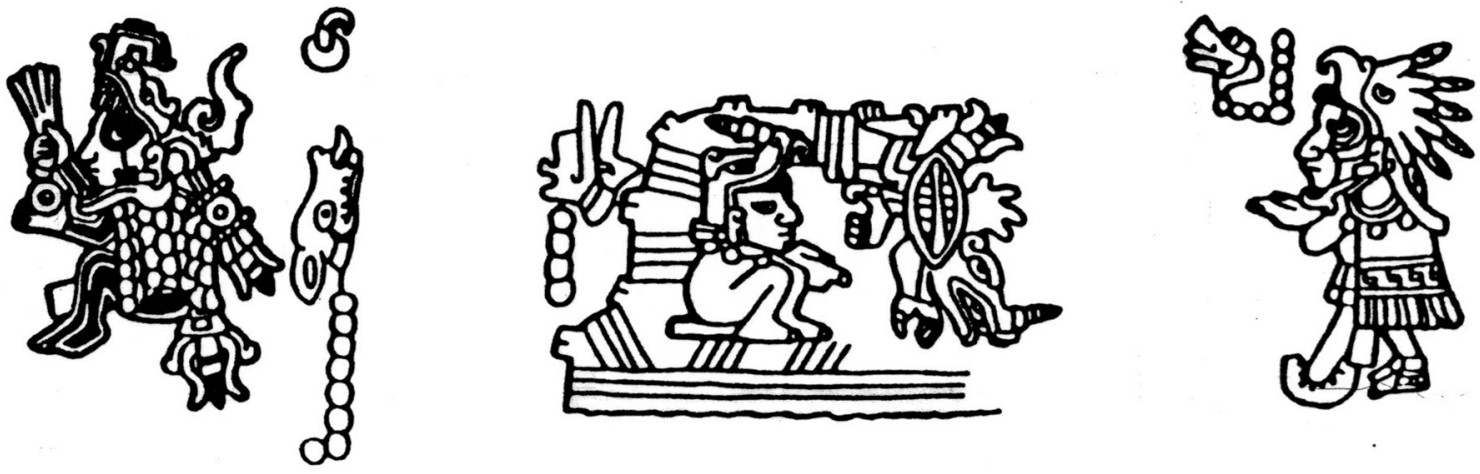

Figura 12. Los sacerdotes yaha-yahui (águila-serpiente de fuego) (modificado de Pohl, 1994b: 66, fig. 27).

piedra verde) eran pendientes colgados de collares (Paddock, 1966: lám. 33). La mayoría de los penates parecen representar bultos mortuorios. Puede ser que se refieran al ancestro del linaje que fundó el reino y que los nobles, como parientes del rey, los llevaran como símbolo de su ascendencia real (fig. 14, p. 28).

\section{LOS COMUNEROS MIXTECOS}

Las grandes capitales como Yanhuitlán y Teposcolula (Yucundaa) estaban divididas en barrios (siqui) ocupados por comuneros. Según Spores (1984: 70), estos siqui eran vecindades y no hay evidencia de que hubieran estado organizados por parentesco. Sin embargo, hay dos tipos distintos de siqui: los ocupados por comuneros libres y los ocupados por siervos.

Los siervos cultivaban los terrenos del rey y no tenían que pagarle tributo. Spores (1983a: 229-230) relata que el rey de Yanhuitlán tenía unos 2000 siervos para cultivar sus terrenos, mientras que el rey de Tecomaxtlahuaca, una capital más pequeña en la Mixteca Baja, tenía unos 800 siervos. Los comuneros libres de los siqui y ñuu tenían que pagar tributo y servicio al rey.

Un documento del siglo XVI enumera los 14 siqui de Yanhuitlán y los restos arqueológicos de, por lo menos, uno de estos siqui ha sido ya identificado. En su reconocimiento arqueológico de Yanhuitlán, Spores (1972) registró los nombres mixtecos actuales de diferentes sitios de la fase Natividad. Uno de estos sitios es Tijua, que seguramente ha de ser el antiguo siqui de Tiquáa mencionado en el documento.

Se han excavado casas de comuneros en Coixtlahuaca (Bernal, 1949), Chachoapan, Yucuita, Nochixtlán (Lind, 1998) y Yucundaa, en Teposcolula (Heredia y Kuttruff, 2007). Estas casas generalmente comprenden uno o dos cuartos con pisos de estuco rojo y un patio de tierra compactada. Uno de los cuartos tiene un fogón y probablemente servía de cocina. Una casa excavada en Nochixtlán tenía un piso circular con un fogón que indica que la cocina era una estructura circular (fig. 15, p. 28; Lind, 1998). También se han encontrado pozos troncocónicos, que posiblemente servían para guardar el maíz, asociados con casas de comuneros en Coixtlahuaca, Yucuita y Yucundaa (fig. 16, p. 29).

Las casas de comuneros que se han excavado en $\mathrm{Yu}$ cundaa (Teposcolula) son algo distintas de las excavadas en Coixtlahuaca, Yucuita, Chachoapan y Nochixtlán. Estas últimas podrían ser casas ocupadas por familias nucleares. Las de Yucundaa probablemente fueron ocupadas por varias familias nucleares emparentadas. Comprenden varios cuartos dispuestos alrededor de un patio estucado (Heredia y Kuttruff, 2007).

Los comuneros no eran enterrados en "sótanos", como la realeza y la nobleza. Para enterrarlos se excavaba un pozo de tamaño adecuado para acomodar el cuerpo en posición fetal (fig. 17, p. 29). 


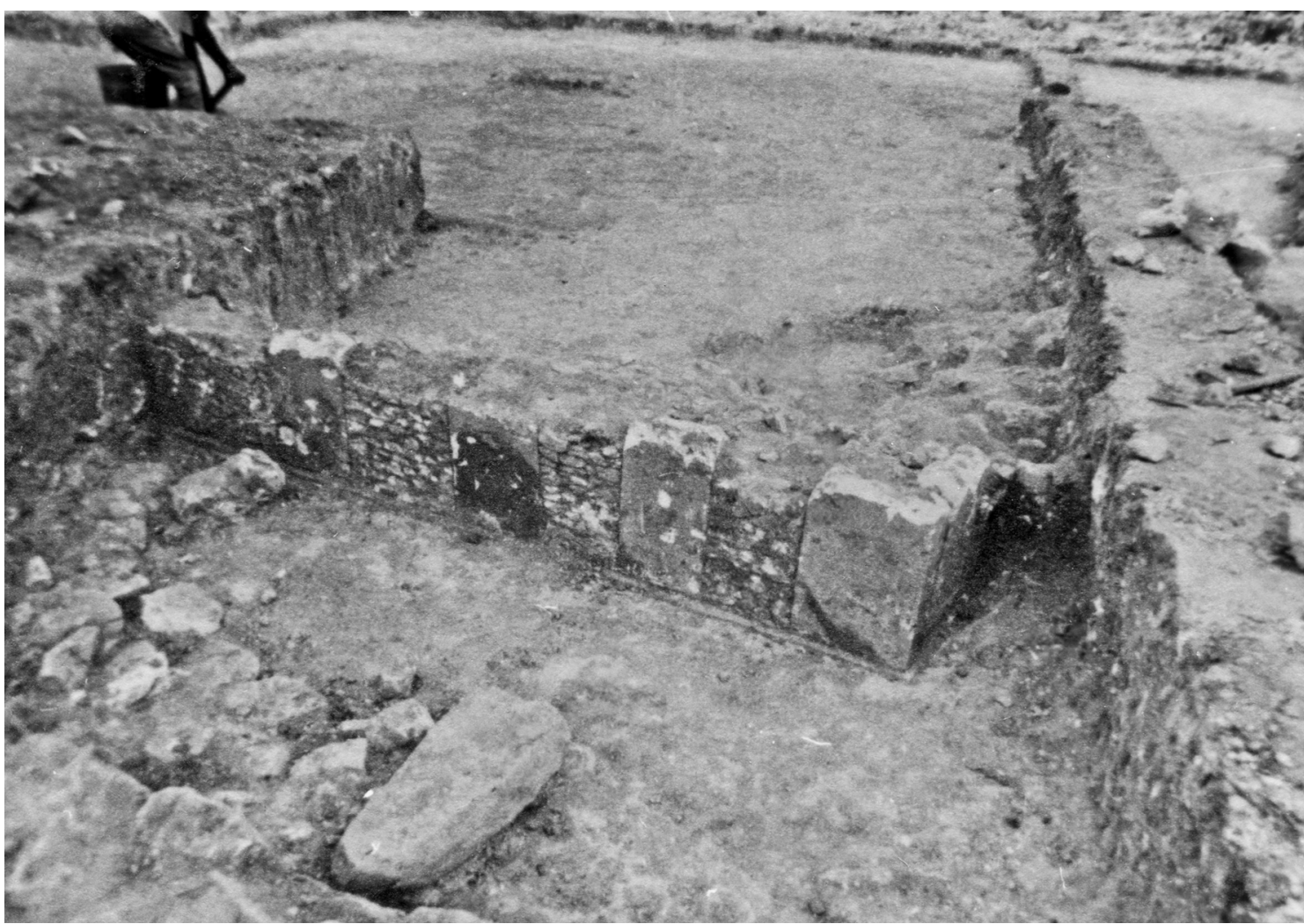

Figura 13. Muros mixtecos de endeque de una casa de nobles en Chachoapan, fase Natividad Tardío.

\section{LA ECONOMÍA MIXTECA}

La economía de los yuhuitayu mixtecos se basaba en el cultivo con coas. El maíz, chía, frijoles, calabazas, chiles, jitomates y maguey se plantaban en casi todos los yuhuitayu. Además, se cultivaba una variedad de verduras y frutas como el nopal, aguacates, cerezas (capulín) y ciruelas. Restos de la mayoría de estas plantas se han encontrado en las excavaciones arqueológicas (C. E. Smith, 1976: 33-39). Los guajolotes y los perros se criaban para comida y se protegían los panales de abejas para la miel. Los habitantes aprovechaban también muchas plantas y animales silvestres. Los documentos mencionan cazadores que se especializaban en la caza de venados, conejos y liebres que entregaban al rey (Dahlgren, 1954: 97).

Aparte de lo que producían, todos los yuhuitayu mixtecos tenían que importar ciertos productos. El rey y la nobleza mantenían un monopolio sobre muchos bienes importados, como la sal, la obsidiana, los textiles finos, el cacao, las plumas finas, piedras preciosas y los metales (Spores, 1984: 84).

Cada yuhuitayu contaba con un mercado en su capital para el intercambio de productos locales e importados, pero no hay evidencia de especialistas de tiempo completo en la economía de la Mixteca (Spores, 1984: 81). Los especialistas de tiempo parcial manufacturaban la mayoría de los productos como la cerámica, las manos y metates, los cestos, los petates y otros bienes que cada casa necesitaba. Sin embargo, en el yuhuitayu de Nochixtlán, muchos de sus habitantes eran comerciantes que viajaban de mercado en mercado cambiando productos locales por productos de lujo (Spores, 1984: 82; Dahlgren, 1954: 246-247). Nochixtlán también era famoso por su producción de cochinilla (Dahlgren, 1954: 141-142). 

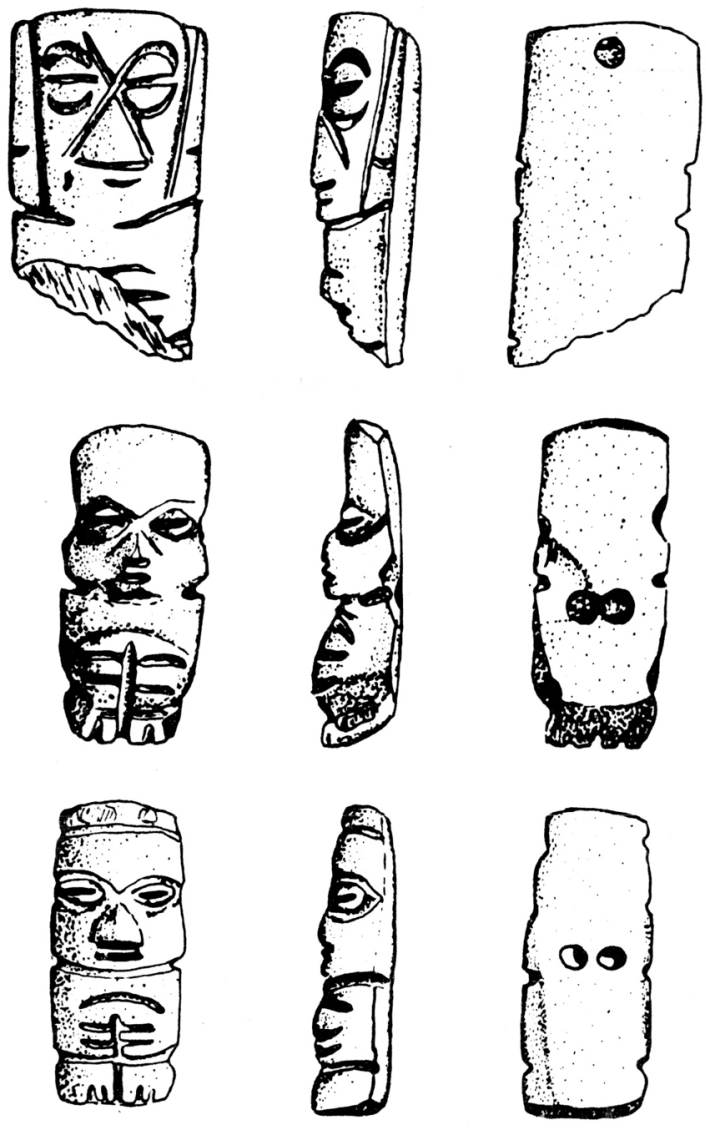

Figura 14. Penates mixtecos de excavaciones en Chachoapan, fase Natividad Tardío. Dibujo de Lynne Dixon.

Pohl (1994a) comenta que miembros de la familia real y de la nobleza eran especialistas que hacían productos de lujo. Producían joyas finas de oro, plata, cobre y piedras preciosas. También hacían capas de plumas finas, textiles finos y cerámica polícroma. Muchos de estos productos de lujo eran regalos que daban los reyes y nobles en casamientos, ceremonias mortuorias, celebraciones de alianzas y ceremonias religiosas importantes. Algunos productos de lujo se guardaban para formar parte de la tesorería real (Dahlgren, 1954: 139).

Existían grandes mercados interregionales en Coixtlahuaca, que recibían productos del Golfo, y en Putla, que recibían productos de la costa del Pacífico. Estos mercados especiales proporcionaban productos para los grandes

\section{CASAN=6}
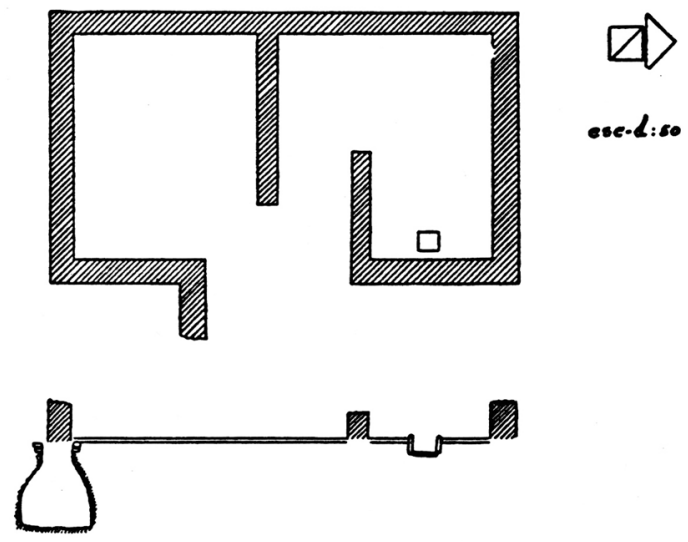

Figura 15. Casa de comuneros en Coixtlahuaca, fase Natividad Tardío (Bernal, 1949: 9, plano 1).

mercados regionales de Tlaxiaco, Teposcolula, Yanhuitlán, Huajuapan y Acatlán. De estos mercados regionales, los productos llegaban a los pequeños mercados de los yuhuitayu. No se ha localizado con seguridad ni se ha excavado ninguna plaza de mercado en la Mixteca hasta la fecha.

\section{LA RELIGIÓN MIXTECA}

Cada yuhuitayu tenía uno o más templos en su capital, aunque las ceremonias religiosas también se llevaban a cabo en lo alto de los cerros, en cuevas y hasta en las ruinas abandonadas del periodo Clásico (Spores, 1984: 92). Los sacerdotes mixtecos (tay saque) eran nobles y, en algunos casos, comuneros (Spores, 1983d: 343; Dahlgren, 1954: 262). Los neófitos hacían cuatro años de entrenamiento ayudando al sacerdote con las actividades rituales y aprendiendo las ceremonias. Luego entraban al servicio del rey. Los sacerdotes tenían que mantenerse célibes durante su tiempo en el sacerdocio y podían alcanzar rangos más altos cada cuatro años, si el rey los promocionaba (Dahlgren, 1954: 309).

Cada yuhuitayu tenía su propia deidad patrona, diferente a la de otros yuhuitayu (Dahlgren, 1954: 261). Sin embargo, había divinidades veneradas en toda la Mixte- 


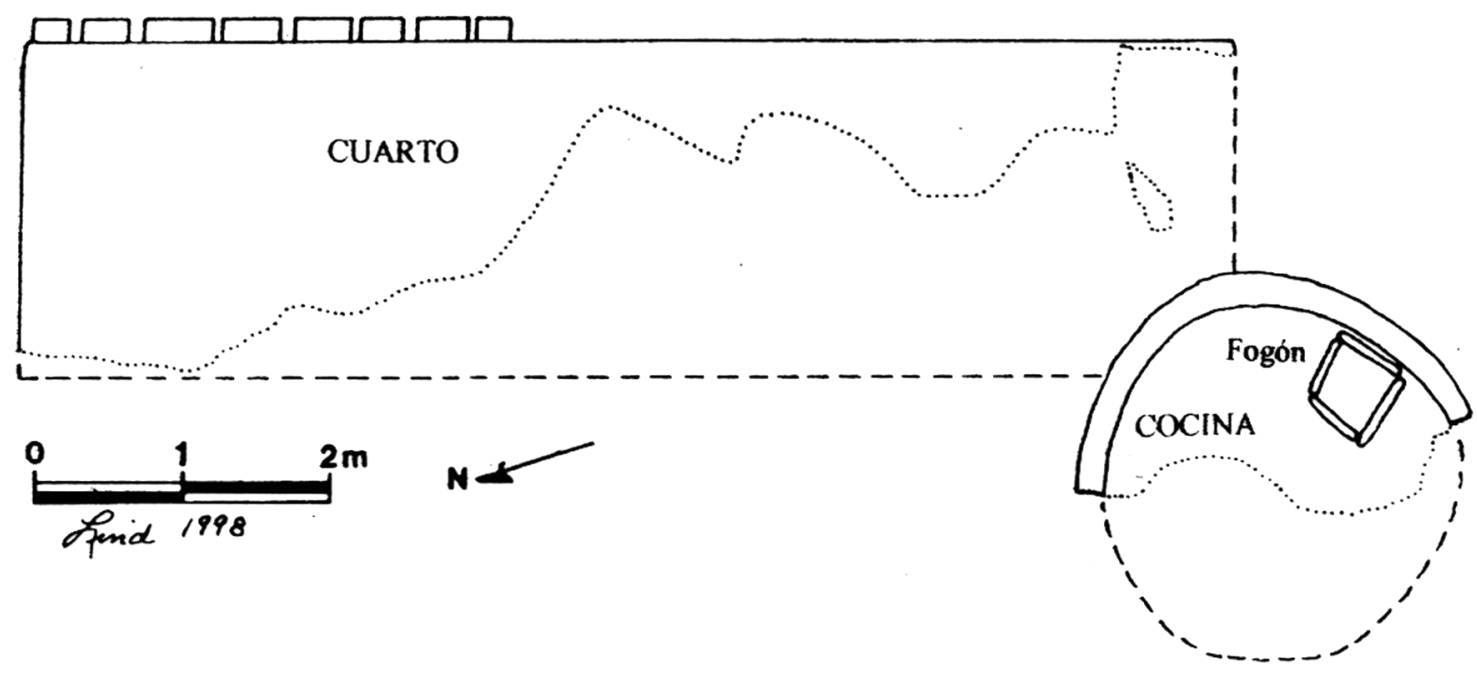

Figura 16. Casa de comuneros con cocina circular en Nochixtlán, fase Natividad Tardío.

ca. El Señor 9 Viento, un héroe divinizado, es parecido al nahua Ehécatl Quetzalcóatl (Furst, 1978: cap. 4), y el Señor 7 Flor era un dios patrón de los nobles. También eran venerados los $\tilde{n} u h u$, espíritus de la tierra, y lo siguen siendo hasta la fecha (Monaghan, 1995: 98-114).

Dzahui, el dios de la lluvia, parecido al nahua Tláloc, era la divinidad más venerada entre los comuneros (Dahlgren, 1954: 299). En los tiempos en que faltaba la lluvia, los sacerdotes, vestidos de Dzahui (como se puede ver en el Códice de Yanhuitlán, Sepúlveda y Herrera, 1994: 106), quemaban copal y ofrecían plumas finas y su propia sangre al ídolo de Dzahui. Luego sacrificaban aves, quemaban una bola de hule y huntaban el hule líquido sobre el ídolo. Finalmente, envolvían cuidadosamente el ídolo en una tela fina y lo llevaban al pico de una montaña, donde sacrificaban a un niño y ofrecían su corazón al dios. Los reyes proporcionaban los materiales y los niños para las ofrendas que hacían los sacerdotes (Dahlgren, 1954: 278-279).

En las excavaciones se han encontrado muchos sahumadores de cerámica crema fina pintados en rojo con la "bigotera" de Dzahui (Lind, 1987). Pero, con la excepción de excavaciones muy limitadas hechas por Bernal (1949: 12-18) en Coixtlahuaca, ningún templo del Posclásico ha sido excavado hasta la fecha.

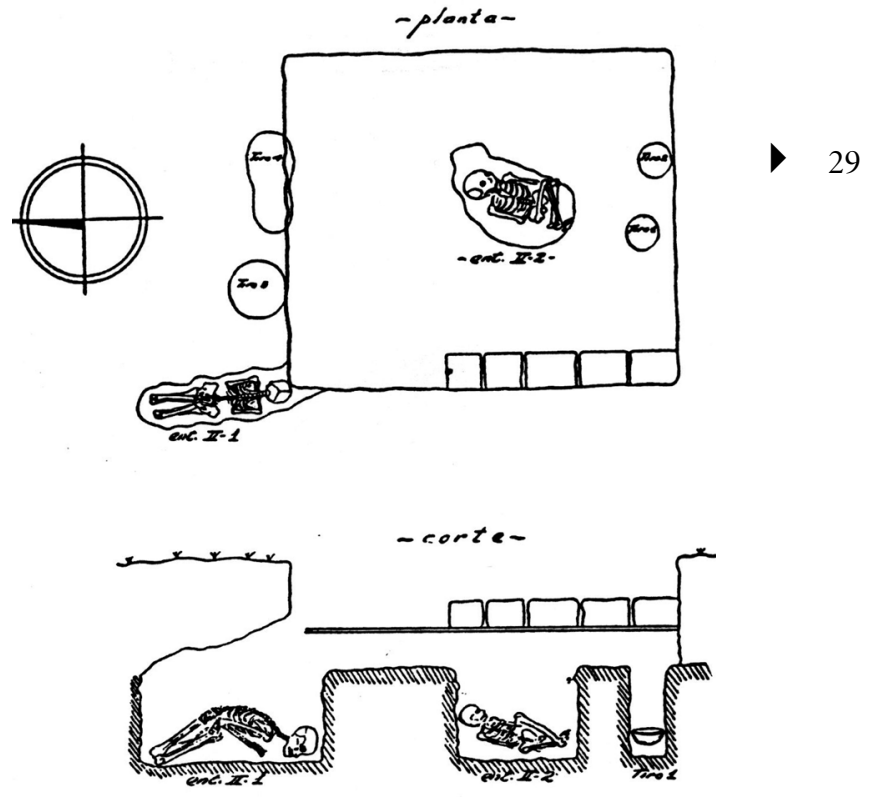

Figura 17. Entierros de comuneros en Coixtlahuaca, fase Natividad Tardío (Bernal, 1994: 13, plano 3).

Dos pueblos en la Mixteca Alta merecen atención porque eran centros religiosos importantes. Achiutla era el centro religioso del Señor 1 Muerte, un dios solar y gran 
oráculo. La gente de toda la Mixteca hacía peregrinaciones a Achiutla (Spores, 1983d: 343). Chalcatongo era el centro religioso de la Señora 9 Hierba, una diosa de la tierra y la fertilidad; también era oráculo (Pohl, 1994b: cap. IV). Cerca de Chalcatongo había supuestamente una gran cueva en la que se enterraba a reyes y reinas de la Mixteca Alta (Dahlgren, 1954: 271-272).

\section{LA CULTURA MIXTECA}

Cuando grupos de pequeñas ciudades-estados contiguas pero independientes, como los yuhuitayu mixtecos, comparten una misma cultura, Hansen (2000) los ha llamado una cultura ciudad-estado. Hansen (2000) ha identificado unas treinta culturas ciudades-estados en el mundo, incluyendo la cultura ciudad-estado mixteca (Lind, 2000). La cultura ciudad-estado mixteca fue el resultado de una muy larga historia de interacción entre los yuhuitayu de la Mixteca Alta, Baja y de la Costa.

Los códices mixtecos dan una buena idea de cuán larga era la historia entre los yuhuitayu. La dinastía mixteca más antigua identificada en los códices es la primera dinastía de Tilantongo en la Mixteca Alta, que comenzó en 990 d.C. con un rey histórico nacido en 942 d.C. (Rabin, 2002). Esta fecha se ubica al principio del Posclásico Temprano y casi 600 años antes de la conquista. Los documentos históricos relatan que un códice con una lista de 24 generaciones de reyes de Yanhuitlán se guardaba en una caja de comunidad en 1582 (Spores, 1967: 94-96). Contando 25 años por generación, este códice nos llevaría a 982 d.C., casi 550 años antes de la conquista.

La dinastía de Tututepec en la Mixteca de la Costa comenzó en 1097, con la conquista de la región por el Señor 8 Venado, que había venido de Tilantongo, a $130 \mathrm{~km}$ de Tututepec. La primera dinastía mixteca de Acatlán en la Mixteca Baja resultó de un casamiento en 1189 entre un señor de Teozacoalco, en la Mixteca Alta, y una señora de Acatlán (Rabin, 2002). Teozacoalco se encuentra a $160 \mathrm{~km}$ de Acatlán. Por toda la Mixteca Alta, Baja y de la Costa los yuhuitayu mixtecos estaban aliados por casamientos reales.

Estas alianzas matrimoniales, el comercio y la religión (la veneración del dios Dzahui y las peregrinaciones a
Achiutla) eran elementos muy importantes para la integración de los yuhuitayu en una cultura común durante un periodo de 600 años. A pesar de ser independientes, de hablar diferentes dialectos (Josserand, Jansen y Romero, 1984) y, a veces, diferentes idiomas, y de estar separados por escarpadas montañas y grandes distancias, los yuhuitayu de la Mixteca Alta, Baja y de la Costa compartían una misma cultura ciudad-estado (Lind, 2000).

\section{CONCLUSIONES}

En los últimos cincuenta años se ha avanzado en los estudios arqueológicos de la Mixteca. Por primera vez tenemos cronologías arqueológicas para las tres regiones de la Mixteca. Se han hecho muchos recorridos arqueológicos en la Mixteca Alta y algunos en la Mixteca Baja y en la Mixteca de la Costa. También, por primera vez, se han emprendido excavaciones en la Mixteca Baja y de la Costa, y más excavaciones en la Alta. Los estudios etnohistóricos también han avanzado mucho en los últimos cincuenta años, con muy buenos estudios recientes del Códice Muro (Hermann, 2003) y los códices cuicatecos Porfirio Díaz y Fernández Leal (Van Doesburg, 2001). Espero que se realicen avances aún más profundos en los próximos cincuenta años, porque todavía hay muchísimo por investigar en la Mixteca.

\section{Bibliografía}

Arriola Rivera, María Victoria y María Teresa Palomares, 2000, "Rescate arqueológico en Huajuapan de León, Oaxaca: sitio Santa Teresa", ponencia presentada en el IV Simposio Bienal de Estudios Oaxaqueños, 6-8 julio, Oaxaca, Oaxaca.

Autry, William O., 1997, "Methods to Derive Population from Suma de Visitas", ponencia presentada en el IV Mixtec Gateway, 8-9 marzo, Las Vegas, Nevada.

Bernal, Ignacio, 1949, "Exploraciones en Coixtlahuaca, Oaxaca”, Revista Mexicana de Estudios Antropológicos, núm. X, pp. 5-76.

_ 1958, "Archeology of the Mixteca", Boletin de Estudios Oaxaqueños, núm. 7. 
Blomster, Jeffrey P., 2002, "What and Where is the Olmec Style? Regional Perspectives on Hollow Figurines in Early Formative Mesoamerica", Ancient Mesoamerica, vol. 13, núm. 2, pp. 171-195.

Burgoa, fray Francisco, 1989, Geográfica Descripción, 2 ts., Miguel Ángel Porrúa, México.

Byland, Bruce E., 1980, Political and Economic Evolution in the Tamazulapan Valley, Mixteca Alta, Oaxaca, Mexico: A Regional Approach, tesis doctoral, Departamento de Antropología, Pennsylvania State University.

Caso, Alfonso, 1938, Exploraciones en Oaxaca, quinta y sexta temporadas 1936-1937, Instituto Panamericano de Geografía e Historia, México.

Cortés, Hernán, 1963, Cartas de Relación, 2a ed., Miguel Ángel Porrúa, México.

Dahlgren de Jordan, Barbro, 1954, La Mixteca: su cultura e historia prehispánicas, Imprenta Universitaria, México.

Diego Luna, Laura, 2007, “El Palacio de Yucundaa”, ponencia presentada en el 72 Annual Meeting of the Society for American Archaeology, Austin, Texas.

Doesburg, Sebastián van, 2001, Códices cuicatecos: Porfirio Díaz y Fernández Leal, Estado de Oaxaca, Miguel Ángel Porrúa, México.

Furst, Jill L., 1978, Codex Vindobonesis Mexicanus I: A Commentary, Institute for Mesoamerican Studies, State University of New York, Albany, Nueva York.

Gaxiola González, Margarita, 1984, Huamelulpan, un centro urbano de la Mixteca Alta, Instituto Nacional de Antropología e Historia, México (Colección Científica, 114).

Hansen, Mogens H. (ed.), 2000, A Comparative Study of Thirty City-State Cultures, The Royal Danish Academy of Sciences and Letters, Copenhagen, Dinamarca.

Heredia Espinoza, Verenice Y. y Carl Kuttruff, 2007, "Arquitectura doméstica en el Pueblo Viejo de Teposcolula, Yucundaa”, ponencia presentada en el 72 Annual Meeting of the Society for American Archaeology, Austin, Texas.

Hermann Lejarazu, Manuel Álvaro, 2003, Códice Muro. Un documento mixteco colonial, Secretaría de Asuntos Indígenas, Gobierno del Estado de Oaxaca, Oaxaca.

Hopkins, Nicholas, 1984, "Otomanguean Linguistic Prehistory”, en J. K. Josserand, Marcus Winter y Nicholas Hopkins (eds.), Essays in Otomanguean Culture History, Vanderbilt University Publications in Anthropology, Nashville, Tennessee, pp. 25-64 (publicación 31).

Josserand, J. Kathryn, Maarten Jansen y María de los Ángeles Romero, 1984, "Mixtec Dialectology: Inferences from Linguistics and Ethnohistory”, en J. K. Josserand, Marcus Winter y Nicholas Hopkins (eds.), Essays in Otomanguean Culture History, Vanderbilt University Publications in Anthropology, Nashville, Tennessee, pp. 141-163 (publicación 31).
Joyce, Arthur, Marcus Winter y Raymond Mueller, 1998, Arqueología de la Costa de Oaxaca: asentamientos del periodo formativo del río Verde Inferior, Estudios de Antropología e Historia Oaxaca, Oaxaca (publicación 40).

Lind, Michael D., 1979, Postclassic and Early Colonial Mixtec Houses in the Nochixtlán Valley, Oaxaca, Vanderbilt University Publications in Anthropology, Nashville, Tennessee (publicación 23).

—_ 1987, The Sociocultural Dimensions of Mixtec Ceramics, Vanderbilt University Publications in Anthropology, Nashville, Tennessee (publicación 33).

$\ldots$, 1994, "Cholula and Mixteca Polychromes: Two Mixteca-Puebla Regional Sub-Styles," en H. B. Nicholson y Eloise Quiñones-Keber (eds.), Mixteca-Puebla: Discoveries and Research in Mesoamerican Art and Archaeology, Labyrinthos Press, Lancaster, California, pp. 79-99.

_ 1998 , "Archeology of the Mixteca: The Direct Historical Approach", ponencia presentada en el 5 Mixtec Gateway in Honor of Dr. Ronald Spores, Las Vegas, Nevada. $\ldots$, 2000, "Mixtec City-States and Mixtec City-State Culture", en Mogens H. Hansen (ed.), A Comparative Study of Thirty-One City-State Cultures, The Royal Danish Academy of Sciences and Letters, Copenhagen, Dinamarca, pp. 567-580.

Lorenzo, José Luis, 1958, Un sitio precerámico en Yanhuitlán, Oaxaca, Instituto Nacional de Antropología e Historia, México (Dirección de Prehistoria, publicación 6).

Monaghan, John, 1995, The Covenants with Earth and Rain: Exchange, Sacrifice, and Revelation in Mixtec Sociality, University of Oklahoma Press, Norman, Oklahoma.

Moser, Chris L., 1977, Nuiñe Writing and Iconography of the Mixteca Baja, Vanderbilt University Publications in Anthropology, Nashville, Tennessee (publicación 19).

Nuttall, Zelia (ed.), 1975, The Codex Nuttall: A Picture Manuscript from Ancient Mexico, The Peabody Museum Facsimile, Dover Publications, Nueva York.

Paddock, John (ed.), 1966, Ancient Oaxaca, Stanford University Press, Stanford, California.

Plunket, Patricia, 1990, "Patrones de asentamiento en el Valle de Nochixtlán y su aportación a la evolución cultural en la Mixteca Alta", en Marcus Winter (comp.), Lecturas históricas del estado de Oaxaca. I. Época prehispánica, Instituto Nacional de Antropología e Historia, México, pp. 349-378 (col. Regiones de México).

Pohl, John, 1994a, "Weaving and Gift Exchange in the Mixtec Codices", en G. Johnson y D. Sharon (eds.), Cloth and Curing: Continuity and Change in Oaxaca, San Diego Museum, San Diego, California, pp. 3-12 (publicación 32). , 1994b, The Politics of Symbolism in the Mixtec Codices, Vanderbilt University Publications in Anthropology, Nashville, Tennessee (publicación 46). 
Rabin, Emily, 2002, “Toward a Unified Chronology of the Historical Codices and Pictorial Manuscripts of the Mixteca Alta, Baja, and Costa: An Overview", en Patricia Plunket (ed.), Homenaje a John Paddock, Universidad de las Américas, Cholula, Puebla, pp. 100-136.

Rivera Guzmán, Ángel Iván, 2000, "La iconografía del poder durante el Clásico en la Mixteca Baja de Oaxaca. Evidencia iconográfica y arqueológica”, Cuadernos del Sur, año 6, núm. 15 , pp. 5-36.

__ 2004, La iconografía de las piedras grabadas de Cuquila y la distribución de la escritura ñuiñe en la Mixteca Alta, Oaxaca, Instituto Nacional de Antropología e Historia, Dirección de Registro Público de Monumentos y Zonas Arqueológicos, México.

Rivera Guzmán, Ángel Iván y Román Piña Chan, 2005, “Algunos resultados del Proyecto Mixteca Baja”, en Ernesto Vargas Pacheco (eds.), IV Coloquio Pedro Bosch Gimpe$r a$, vol. 2, Instituto de Investigaciones Antropológicas, Universidad Nacional Autónoma de México, México, pp. 667-693.

Rodríguez Cano, Laura, Ángel Iván Rivera Guzmán y Júpiter Martínez, 1996, "Algunas reconsideraciones sobre la escritura ñuiñe”, Arqueología, núm. 15, Instituto Nacional de Antropología e Historia, México, pp. 79-89.

Rojas González, Francisco, René Barragán Áviles y Roberto De La Cerda Silva, 1957, Etnografía de México: síntesis monográficas, Instituto de Investigaciones Sociales, Universidad Nacional Autónoma de México, México.

Sepúlveda y Herrera, María Teresa, 1994, Códice de Yanhuitlán, Instituto Nacional de Antropología e Historia, Benemérita Universidad Autónoma de Puebla, México.

Smith, C. E., 1976, Modern Vegetation and Ancient Plant Remains of the Nochixtlán Valley, Oaxaca, Vanderbilt University Publications in Anthropology, Nashville, Tennessee (publicación 16).

Smith, M. E., 1973, Picture Writing from Ancient Southern Mexico: Mixtec Place Signs and Maps, University of Oklahoma Press, Norman, Oklahoma.

Spores, Ronald, 1967, The Mixtec Kings and Their People, University of Oklahoma Press, Norman, Oklahoma. , 1972, An Archaeological Settlement Survey of the Nochixtlán Valley, Oaxaca, Vanderbilt University Publications in Anthropology, Nashville, Tennessee (publicación 19).
, 1974, "Marital Alliance in the Political Integration of Mixtec Kingdoms”, American Anthropologist, vol. 76, núm. 2, pp. 297-311.

__ 1983a, "The Origin and Evolution of the Mixtec System of Stratification", en Kent Flannery y Joyce Marcus (eds.), The Cloud People, Academic Press, Nueva York, pp. 227-238.

— 1983b, "Postclassic Settlement Systems in the Nochixtlán Valley”, en Kent Flannery y Joyce Marcus (eds.), The Cloud People, Academic Press, Nueva York, pp. 246-248.

, 1983c, "Postclassic Mixtec Kingdoms: Ethnohistoric and Archaeological Evidence”, en Kent Flannery y Joyce Marcus (eds.), The Cloud People, Academic Press, Nueva York, pp. 255-260.

, 1983d, "Mixtec Religion”, en Kent Flannery y Joyce Marcus (eds.), The Cloud People, Academic Press, Nueva York, pp. 342-345.

— 1984, The Mixtec in Ancient and Colonial Times, University of Oklahoma Press, Norman, Oklahoma.

__ 1993, “Tututepec: A Mixtec Conquest State", Ancient Mesoamerica, vol. 4, núm. 1, pp. 167-174.

_, 2005 , "Informe sobre las excavaciones en Yucundaa, Pueblo Viejo de Teposcolula”, Acervos, núm. 29, pp. 70-74.

Terraciano, Kevin, 2001, The Mixtecs of Colonial Oaxaca: Nudzahui History, Sixteenth through Eighteenth Centuries, Stanford University Press, Stanford, California.

Urcid, Javier, 1993, "The Pacific Coast of Oaxaca and Guerrero: The Westernmost Extent of Zapotec Script, Ancient Mesoamerica, núm. 4, pp. 141-165.

__ 1996, “ZZapoteca o ñuiñe?: Procedencia de una lápida grabada en el Museo Etnográfico de Frankfurt am Main”, Mexicon, vol. 18, núm. 3, pp. 50-56.

Winter, Marcus, 1990, “Oaxaca prehispánica: una introducción”, en Marcus Winter (comp.), Lecturas históricas del estado de Oaxaca. I. Época prehispánica, Instituto Nacional de Antropología e Historia, México (col. Regiones de México).

__ 1997, "Yucuita: An Archaeological Site in the Nochixtlán Valley, Mixteca Alta, Oaxaca, México”, ponencia presentada en el 4 Mixtec Gateway, Las Vegas, Nevada.

__, 2007, Cerro de las Minas: arqueología de la Mixteca Baja, Consejo Nacional de la Cultura y el Arte, Instituto Nacional de Antropología e Historia, Oaxaca. 